syphilis may possibly account for such when the accoucheur is in no way to blame. The following cases I have noted.

CAsE 1.-A woman, aged thirty-nine years, complained of pelvic pain and backache. She had suffered from discharge for twelve months. She had had eight children; five had died, and there had been three still births and one abortion. She was suffering from prolapsed uterus; the perineum was absent, and she stated that forceps were used in one of her confinements. The pharynx was ulcerated.

CAst 2.-This patient three years ago had a bad confinement and the perineum was torn. She made a tedious recovery, the lochia lasting five weeks. During her pregnancy the hair fell out and she bad suffered from ulcerated throat since. The uterus was prolapsed.

CASE 3.- This patient, aged thirty years, suffered from falling womb and discharge since the birth of a child ten years ago. There had been two live births and two abortions. She is subject to sore-throats and the pharyox is ulcerated. The vaginal mucous membrane shows a hyperæmic, patchy, measly condition. The lips of the urethra are in a purple, swollen condition. The perineum shows the cicatrix of previous repair, but is thin and papery, and the uterus is prolapsed.

CASE 4.-This patient, aged forty-five years, had been married twenty-six years. Her husband died from hemiplegia some years ago. One child was born twenty-five years ago, but died in infancy. The patient is now out of health, is suffering from menorrhagia, erosion of the os, profuse leucorrhcea, excoriation of the vagina, prolapse of the uterus, and ulcerated tags of previous rupture of the perineum.

CASE 5.-This patient had been married twice. Her first husband died from cerebral trouble. By him she had four children and one abortion. In three months from the second marriage abortion occurred, followed by eruption on the skin attributed to fish diet. The pharynx and tonsils are now excoriated and the voice is hoarse, while there is scattered acne on the back. Perineorrhaphy was performed after her first confinement.

CASE 6.-This patient complained of agony in intercourse She has superficial sores of the internal labia, vaginitis, and endometritis. The pharynx is ulcerated and the glands are enlarged in the groin. The cicatrix of a repaired perineum is exquisitely tender to the touch.

CASE 7.-This patient, aged twenty-eight years, complained of pain in the back and groin. She bad been married nine years. There had been four live births and one abortion. She had suffered from discharge for eight years. She was regular, but lost a great deal. Her hair fell out during the last conception, which ended in abortion. She had sore-throats at the same time, and the pharynx is now ulcerated. She has always lost a great deal of blood at her confinements. The cervix is split and everted.

CASE 8.-This patient was a woman, aged fifty years. Two girls were born in the first two years after marriage. Then the husband was very ill with " rheumatic fever." An abortion followed, then a live bixth, then an abortion, and then two live births. The confinements have always been bad, with six weeks of lochia. After the second girl was born bleeding continued for three months. She now complains of abdominal and rectal pain. On vaginal examination the os uteri was found to be split and tethered to the vagina by bands in every direction, and the rectum is drawn in.

I would point out in connexion with such cases that labour is often protracted from uterine inertia, often necessitating forceps. The post-partum hæmorrhage is profuse and the lochia are prolonged. It is not very uncommon to meet with adhesions of the os uteri to the vagina, of increasing obstructive dysmenorrhœa, and sterility after one conception in parous women. The fibrous adhesions and fibroid condition met with in dilating the cervical canal are well known. Syphilitic stricture of the cervical canal or os uteri is apparently analogous to syphilitic stricture of the urethra in the male, and all the above-mentioned conditions may well illustrate some of the less ostensible symptoms of syphilis in parous women.

A further question follows. Why do plastic operations in women, undertaken with so much care and skill, often fail? The value of mercury in so many cases of pelvic disease in parous women not only testifies to a syphilitic basis, but probably makes it essential that mercurial treatment in many cases should go hand in hand with operative procedure.

Grosvenor-street, W.

\section{A CASE OF ANKYLOSIS OF ALL THE' JOINTS WITH COMPLETE CLOSURE OF THE JAWS, IN WHICH THE. POWER OF MASTICATION WAS RESTORED BY DIVISION OF THE NECKS OF THE LOWER JAW :}

WITH SOME REMARKS ON THE OPERATIVE TREATMENT OF CASES OF ANKYLOSIS OF THE TEMPORO. MAXILLARY JOINT,

BY CHARLES A. MORTON, F.R.C.S. ENG.

SURGEON TO THE PRISTOL GENERAL HOSPITAT AND PROTESSOR OF SURGERY IN UNIVERSITY COLLEGE, BRISTOL.

A MAN, aged fifty-seven years, was sent to we at the Bristol General Hospital by Mr. W. F. Carter, of Bristol, in October, 1896. In all the joints movement was limited, and in most there was complete fixation. The spine and head were perfectly rigid. Deformity was marked both in the large joints and in those of the hands and feet. In some joints where slight movement was possible there was coarse grating, and around a few joints distinct ostesphytic out. growths were present. Muscular wasting was extreme; the skin of some of the fingers was glossy, and some of the nails were of extraordinary thickness. The thickening of the nails was not present in all the fingers. The joint troubles began fourteen years previously in the knees, and the fingers were affected after the larger joints. He was able to walk with sticks until nine years ago. For the last six years he had been confined to bed and unable to feed himself, and for four years he had been unable to open his jaws and therefore unable to take solid food, and had simply sucked fluids between his teeth. He had had no joint trouble in early life, nor was there any family history of such disease. The following is a description of the condition of all the joints. Both knees were absolutely fixed at a right angle. The bony outline was very prominent from the wasting of the muscles, but no osteophytic growths were discovered. The tendons in the popliteal space did not feel contracted. No movement was detected in either hip.joint There was limited movement in the left ankle, but the right ankle was almost completely fixed. All the toes of the left foot except the great toe were hyper-extended (some to a right angle with the dorsum), and the heads of the metatarsal bones from which they were displaced could be felt from the sole. The middle three toes of the right foot were in the position of hammer-toes. The nails on several toes were of extraordinary length and thickness. The left wrist was flexed almost to a right angle with the forearm and quite ankylosed. The fingers of the left hand were all flezed at the metacarpo-phalangeal joints, and there was marked deviation to the ninar side. Movement in the finger joints was much limited. There was marked osteophytic outgrowth about the heads of the metacarpal bones. The nails on some of the fingers were almost normal, on others they formed a horn mass half an inch in thickness, and the skin. of the fingers was glossy. There was no grating in any of the joints. The left thumb was also flexed at the metacarpophalangeal joint, but was hyper-extended at the terminal one and movement in its joints was as limited as in the fingers. The right wrist was slightly flexed and very little movement was possible in it. All the fingers of the right hand were hyper-extended at the metacarpo-phalangeal joint, flexed at the middle phalangeal joint, and hyper-extended again at the terminal joint. 'Ihere was hardly any movement possible in any of the joints, and osteophytic outgrowths were present on the dorsal aspect of the digital extremities of the first phalanges forming the middle phalangeal joint. The position of the right thumb was the same as the left. There was slight grating in its metacarpo-phalangeal joint. The left elbow was quite ankylosed and was much more flexed than a right angle with the upper arm. In the right elbow there was slight movement which was painful, and there were some sharp osteophytic outgrowths from the inner

1 A paper read before the Bath and Bristol Branch of the British Medical Association. 
condyle. In the left shoulder rotation was possible to a slight extent, but was accompanied by coarse grating. In the cight arm the movement at the shoulder was wholly scapular. There was no movement in any part of the spine, but no excessive bony growth could be detected. The chest only moved slightly on deep inspiration; in quiet breathing the abdominal wall alone moved. There was no vidence of rotation of the atlas on the axis, and it was doubtful whether there was any movement between the atlas and the occipital bone.

There is so much confusion between the terms chronic theumatism, rheumatic arthritis, and rheumatoid arthritis that it would not perhaps be profitable to discuss at length the nature of the joint lesions, but taking the definite disease which is perhaps most clearly distinguished by the term osteo-arthritis we may inquire whether it was of this nature. The deformity, the coarse grating in the joints, the osteophytic outgrowth, and the glossy skin all point to the disease being a form of osteo-arthritis. On the otber hand, true ankylosis, that is, ankylosis which is not merely the result of locking of osteophytic outgrowths, is rare in osteo-arthritis. In this case the fixation of the joints was clearly not due to osteophytic outgrowths, for they were only present around a few joints and were absent in many which were absolutely fixed. I cannot find the record of any case of ankylosis of the temporomaxillary joints in osteo-arthritis, though they have become ankylosed from traumatism and suppurative arthritis in several cases. The first time the condyle was excised was for osteo-arthritis. There was no ankylosis, but great renlargement of the condyle, producing marked deformity of the jaw. This was Professor Humphry's case, and was published in the Medical Association Journal in 1856. ${ }^{2}$ In another case (one of Mr. Heath's) ${ }^{3}$ there was also enlargement of the condyle, and a bony mass united it to the malar bone. In one recorded case of ankylosis of this joint, to which reference will be again made, the patient had had rheumatic fever and suffered from recurrent sub-acute attacks.

In my own case there was no evidence of enlargement of the condyles, but there was complete fixation of the joint, so that the jaws could not be opened. It was, of course, impossible to tell whether the ankylosis affected one or both joints. To remedy such a condition either the adhesiun in the joint must be broken down, or the joint excised, or a new joint formed. It was impossible in this case to lever open the jaws, as the teeth could not be separated at all, and nence no wedge or screw.gag could be introduced; and, moreover, Mr. Paul Swain has shown, from the collected records of cases, that all such attempts fail. ${ }^{5}$ A new joint has usually been formed by removal of a wedge of bone just in front of the angle of the jaw-Esmarch's operation. The respective advantages and disadvantages of the two operations I will consider presently. I decided on excision of the condyle or condyles, and the operation I am about to describe was performed in exactly the same way on both sides, as the ankylosis was found to be bilateral. It was done on Oct. 27th, 1896. An incision was made about one inch in length parallel with, and a quarter of an inch below, the lower border of the zygoma, commencing just in front of the ear and extending forwards, therefore beginning over the temporal artery, but not deep enough at that spot to wound it. A portion of the parotid gland, superficial fascia, and fat were divided, and several small vessels were tied. The masseter was then exposed and was divided, and I came down on the zygoma, with the neck of the jaw fixed to it as if it were one bone. There was no sign of any joint, nor could any movement be made out on attempting to open the jaw. I then inserted a curved narrow copper spatula under the neck from behind, so as to separate it from the internal maxillary and other vessels, and divided the neck with an Adam's saw and a few chisel cuts. When I found the joint was completely obliterated I gave up the idea of excising the condyle. I saw no branches of the facial nerve on the right side; on the left, when retracting the fascia over the masseter, the orbicularis palpebrarum and oris both twitched. When separating the divided portions of the neck on the left side with a periosteal elevator some rather free bleeding occurred from a vessel behind the neck-probably a torn venous branch-and I had to leave a pair of pressure forceps on, as it was impossible to tie it. These were removed

$$
2 \text { Page } 61 \text {. }
$$

next day, and the wounds healed without suppuration. After divisions of both necks I was able to lever the jaw open, so that there was a space of a quarter of an inch between the teeth, and a few days after the operation he could open it one-eighth of an inch more and could eat all kinds of solid food. Nearly a month after the operation I opened the jaw with a screw gag under chloroform so that there was nearly an inch space between the teeth. I heard in February of this year that he was still able to eat solid food easily. ${ }^{\circ}$ There was a little paresis of the left orbicularis palpebrarum after the operation, but with the application of the faradaic current this soon passed off.

After excision of the condyle or division of the neck of the jaw the difficulty in forcing open the jaw lies in the contracted condition of the muscles, especially the temporal muscle. After dividing the neck on both sides in this case I found the movement at the point of section free, bat the contracted temporal and masseter muscles kept the jaws from separating to any extent, and I had to gradually lever them open in order to obtain a satisfactory result, a process which was repeated some weeks after the operation. I believe that it is best to make only a horizontal incision below the zygoma, and not a vertical one at all, as division of branches of the facial nerve is more likely to occur with the latter, however short, and I believe it would not give a distinctily greater access to the joint than a fairly long horizontal ir cision.

The respective advantages and disadvantages of excision of the condyle and Esmarch's operation of removal of a wedge-shaped piece of bone from just in front of the angle of the jaw remain to be considered. It seems to me that if we can liberate the joint so that it will not again become fixed it would be much better to do so than to perform Esmarch's operation. After a double Esmarch's operation the body would be quite cut of from the ascending rami, so that the masseters, temporals, and pterygoids could not act on the movable portion, and the ability to close the jaw would be lost; nor could any antero-posterior or lateral masticatory movements be performed. It seems possible that in time the buccinator might partially take on the action of the masseter and be able partly to close the jaw. That the power of closure does return is shown by the records of cases in which the operation has been performed, but it does not become possible for lateral masticatory movements to be carried on. If the wedge in Lismarch's operation is taken out so far back as to include the angle, as has been done in a few cases, then the attachment of the masseter would not necessarily be wholly separated from the movable portion, and closure could be feebly effected by the portion left attached. On the other hand, some surgeons have brought forward this very severance of the movable portion of the jaw from the masseter and other muscles which close the jaw as a great advantage of Esmarch's operation, for it, of course, tends to prevent the divided portions of jaw being forcibly drawn together and so reunited. The most serious objection to operation on the joint is the unfortunate tendency there is for it to become again fixed after operation; and no doubt the temporo-maxillary joint is in a somewhat dangerous locality for operative interference, with the internal maxillary artery so close to it beneath and the branches of the facial nerve lying over it in the way of the necessary incision. Temporary paralysis of some of the branches of the nerve is not uncommon after the operation, and in one case the external carotid artery was wounded. The facial artery might be wounded in Esmarch's operation but could probably be pushed out of the way, or if divided could be easily secured, whereas the internal maxillary artery if wounded might be very difficult to secure, as it lies behind the junction of the neck and ascending ramus. The inferior dental artery is divided in Esmarch's operation, but does not bleed when sawn through, nor does division of the inferior dental nerve give rise to any trouble. If Esmarch's operation is performed for fixation of the jaw due to a unilateral cause, then the muscles of the side on which the operation has not been performed will, of course, close the jaw, but anteroposterior and lateral masticatory movements would necessarily be very imperfect from the inability of the external pterygoid, masseter, and temporal muscles to act on the side from which the wedge had been removed. We should, indeed, expect the body of the jaw to be somewhat pushed over to the side operated on by the external pterygoid of the

6 A later report (July 15th, 1897) caid that he could eat solid food.

but could not open the jaw as widely as in February. 
other side. It has sometimes happened after Esmarch's operation on both sides that the power of swallowing has been interfered with from loss of a fixed point for action of the elevators of the hyoid bone when the body of the jaw has been detached from the rami. A case under Mr. Bennett's care ${ }^{8}$ so well illustrates the advantages and disadvantages of Esmarch's operation and excision of the condyle that I will give a short abstract of it. The patient suffered from complete fixation of the jaw. Mr. Howse, at Gay's Hospital, exposed both temporo maxillary joints, finding very firm ankylosis, and excised both condyles. The joint again became fixed, and $\mathrm{Mr}$. Howse then removed a portion of one ascending ramus, but this subsequently united. Mr. Bennett then performed Esmarch's operation on both sides with a week's interval. The jaw opened after the second operation, but the patient was quite unable to close it, and as the elevator muscles of the hyoid bone had no longer a fixed point of attachment he became unable to swallow and had to be fed by a tube passed through the nose and down the pharynx for two days. The jaw was then fixed in position by an elastic bandage and the power of swallowing returned. The power to close the jaw also ultimately returned. Mr. Paul $S$ wain reports ${ }^{9}$ a case of bilateral ankylosis in which he removed a triangular piece of bone from both angles of the jaw at one operation with very satisfactory resulte. There was no interference with swallowing, and no mention is made of inability to close the jaw. Doubtless some anterior fibres of the muscles were attached to the lower jaw in front of the section of the bone, and enabled the patient to close the jaw, and thus give the hyoid muscles their fixed point for action. There are, of course, many cases in which we have no choice between an operation on the joint and Esmarch's operation-cases in which the jaw is fixed by a dense cicatrix such as may follow cancrum oris or injury to the cheek or jaws. In such cases we must make a false joint in front of the cicatrix, but they are almost always unilateral.

$\mathrm{Mr}$. Paul Swain has collected ${ }^{10}$ the records of twenty cases of operation for closure of the jaws the result of injury or disease of the temporo-maxillary articulation. He found that out of this number seven resulted from the after effects of scarlet fever, three from measles and subsequent otorrhcea, three from rheumatism, two from affections of the teetb, and five from injury. In elevan cases the condyle or a portion of the neck was excised, and in five Eimarch's operation was performed. To the cases collected by Mr. Paul Swain must be added four recently published by Mr. Arbuthnot Lane. ${ }^{11}$

CASE 1.-Bony ankylosis after fracture of the zygoma. The upper and posterior angle of the jaw with a portion of the temporal bone to which it was fused was excised with good result.

CASE 2.-Bony ankylosis from old suppurative arthritis, with very imperfect development of the jaw. The same operation was performed, and the body of the jaw was divided as well to overcome the deformity. The result was good.

CaSE 3 - Bony ankylosis after scarlet fever. Same operation and result.

CASE 4.-Bony ankylosis after abscess in the neighbourhood of the jaw. Same operation and result.

All these patients were children. Mr. Lane has operated once in an adult and obtained a very good result for a time,
but relapse took place and he had to remove more bone. He lays stress on the difficulty of thoroughly free removal of bone in these cases, as all trace of the joint has disappeared and the neck is ill developed, but believes that it must be freely removed to ensure a successful result. ${ }^{12}$

Clifton, Bristol.

$$
\begin{aligned}
& 8 \text { Transactions of the Clinical Society, vol. xxii. } \\
& \text { y THE LANCE'T, July 28th, 1894, p. } 189 . \\
& 10 \text { THE LA vCET, July 28th, 1894, p. } 187 \\
& 11 \text { Transactions of the Clinical Society. 1896, p. } 1 .
\end{aligned}
$$

12 Since sending this paper for publication a very valuable contribution from Dr. Cabot, of Boston, on the Surgical Treatment of Ankylosis of the Temporo-maxillary Articulation has been published in THE
LANCET of Aug. $7 \mathrm{th}, \mathrm{p}$. 304, and $I$ am interested to see tbat Dr. Cabot LANCET of Aug. 7th, p. 304, and I am interested to see that Dr. Cabot
advocates division of the condyle in preference to Esmarch's method, and records seven cases in which he performed this operation.

Dr. Granville Bantock has been elected an Hororary Fellow of the Obstetrical Society of Edinburgh.

\section{NOTES ON A CASE OF PAN- HYSTERECTOMY.}

BY M. U. O'SULLIVAN, L.R.C.P. EDIN.

I AMr sure that every surgeon of experience in the operation of abdominal pan-hysterectomy will admit at once that the chief difficulties are encountered in dealing with the Hoos of the pelvis and roof of the vagina. It has long appeared to me that a suitable vaginal guide would not only materially facilitate operative technique at this juncture, but would obviate the danger of encroaching too much on the roof of the vagina. In my first six cases of complete extirpa. tion I resorted to the abdomino-vaginal method, com. mencing the operation as in the first stage of raginal hysterectomy; but this method is open to the objection that upon opening the peritoneal cavity some specia\} indication may be found against completing the operation on the lines originally intended, leaving the patient with a vaginal wound to still further hamper her recovery. Mr. Bowreman Jessett, in this operation, used a Ferguson

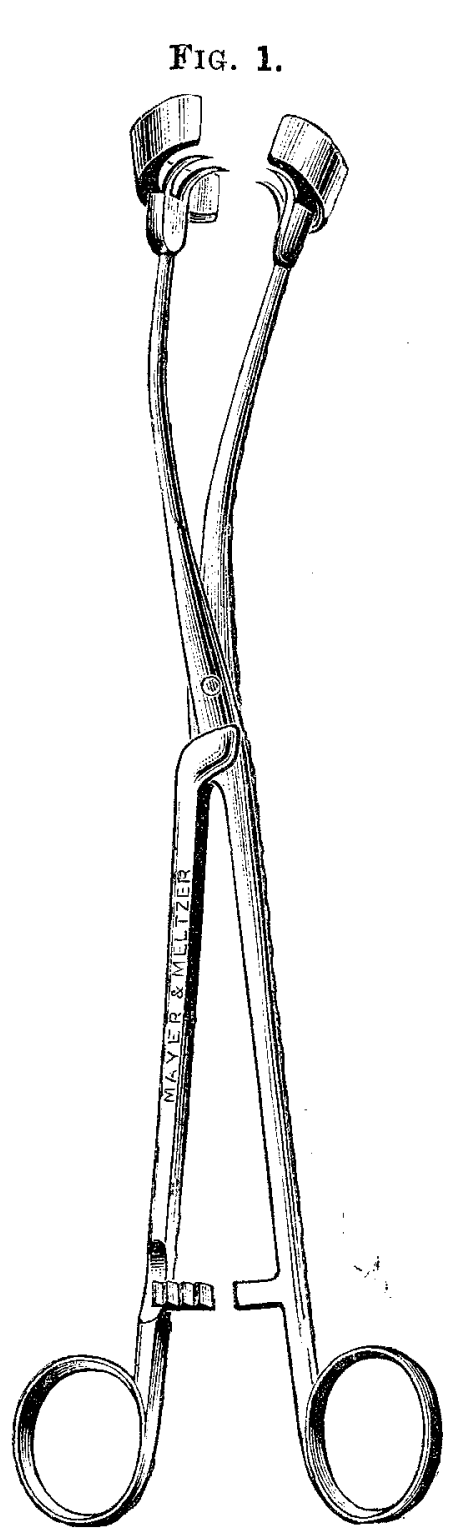
speculum, pushed up by an assistant as a guide; but the difficulty-or, rather, I should say, the hopelessness - of keeping the vaginal cerviz in the vast majority of "fibroids" within the lumen of a speculum is at once obvious. Other surgeons have used the finger of an assistant pushed up into the vagina as a guide to cut down upon, bu this is a procedure not likely to recommend itself to the precise and careful operator. The vaginal forceps (Fig. 1) and director, of which illus. trations appear, has been used in four cases with much advan. tage to the patient and with the greatest satisfaction to myself. It was made after $m y$ direction by Messrs. Mayen and Meltzer. I give the notes of one case.

A woman, aged forty years, single, was admitted to the Women's Hospital, Melbourne, on July $8 ; \mathrm{h}, 1896$. The catamenia first appeared at the age of twelve years; she was regular up to two years ago, but the menses bad been irregular, profuse, and painfud during the past two years. During the past three monthe she had complained of severo pain in the right iliac fossa and sacral region, frequency and pain in micturition, bear. ing aown, \&c. On examina. tion, a rounded median tumorr of hard consistence could be felt filling the pelvis and extending above the umbilicus. The cervix uteri was pushed far back in the hollow of the sacrum. The patient was prepared as for cœliotomy and vaginal bysterectomy and was placed in the lithotomy position, the lower limbs being separated by assistants. A Sims speculum was passed, and the vagina thorsughly scrubbed with a 1 in 500 perchloride solution. The cervix was now grasped with the combined vaginal forceps and director, the blades of which were firmly locked and the patiens returned to the supine position. The abdomen was opened by a free incision extending from above the umbilicas to within a short distance of the pubes, and the tumous "delivered"-this being very materially facilitated by an assistant steadily pushing the tumour and nterus towards the abdominal cavity, on the forceps and director, within the 